\title{
Dirseğin travmatik çıkıkları
}

\section{Traumatic dislocations of the elbow}

\author{
Yakup Barbaros Baykal, Vecihi Kırdemir
}

Süleyman Demirel Üniversitesi Tıp Fakültesi Ortopedi ve Travmatoloji Anabilim Dalı, Isparta

Dirsek çıkıkları omuz çıkıklarından sonra en sık görülen çıkıklardır. Genellikle açık el üzerine düşme sonucu meydana gelir. Tanı çoğunlukla klinik muayene ve direkt grafiler ile konulabilir. Bazı çıkıklara eşlik eden başka yumuşak doku ve kemik yaralanmalar olabilir. Tedavi konservatif veya cerrahi olabilir. Tekrarlayıcı çıkıklar, dirsek eklem sertliği, heterotopik kemikleşme ve nörovasküler komplikasyonlar izlenebilir.

Anahtar sözcükler: dirsek eklemi; eklem çıkı̆̆ı; cerrahi
Elbow dislocations are the most common dislocations after shoulder dislocations. They usually occur as a result of falling on the open hand. Diagnosis can be made mostly by clinical examination and direct radiographs. There may be other soft tissue and bone injuries accompanying some dislocations. Treatment can be conservative or surgical. Recurrent dislocations, elbow joint stiffness, heterotopic ossification and neurovascular complications can be observed.

Key words: elbow joint; joint dislocation; surgery

b) Sekonder statik yapılar: kapsül, radyokapitellar eklem, fleksör ve ekstansör tendon orijinleri,

2. Dinamik yapılar: eklemi geçen kaslar.

\section{DEĞERLENDIRME}

Klinik olarak dirsek şiş, deforme ve ağrılıdır. Hasta ağrı nedeni ile dirseğini oynatamaz. Tüm dirsek yaralanmalarında olduğu gibi dirsek çıkıklarında da nörovasküler muayene ihmal edilmemelidir. Sıklıkla ulnar sinir tutulumları izlenir. Gecikmiş olgularda ise kompartman sendromu açısından uyanık olunmalıdır. Tanı anteroposterior (AP) ve yan grafiler ile rahatlıkla konur. Eşlik edebilecek kırıklar için oblik grafiler gerekebilir. Çıkığa eşlik eden diğer kemiksel patolojiler sıklıkla direkt grafide görülebilir, şüpheli durumlarda bilgisayarlı tomografi (BT) gerekebilir.

Dirsek çıkıklarını derecesine ve yönüne göre sınıflamak mümkündür:

1. Basit çıkıklar-başka kemik patoloji yoktur (Şekil 1),

2. Kompleks çıkıklar-çıkık yanında başka kemik patolojiler mevcuttur, eklem yüzü bozulabilir (Şekil 2).

- İletişim adresi: Prof. Dr. Yakup Barbaros Baykal, Süleyman Demirel Üniversitesi Tıp Fakültesi, Ortopedi ve Travmatoloji Anabilim Dalı, Isparta Tel: 0532 - 6165266 e-posta: barbarosbaykal@gmail.com

- Geliş tarihi: 9 Kasım $2018 \quad$ Kabul tarihi: 9 Kasım 2018 


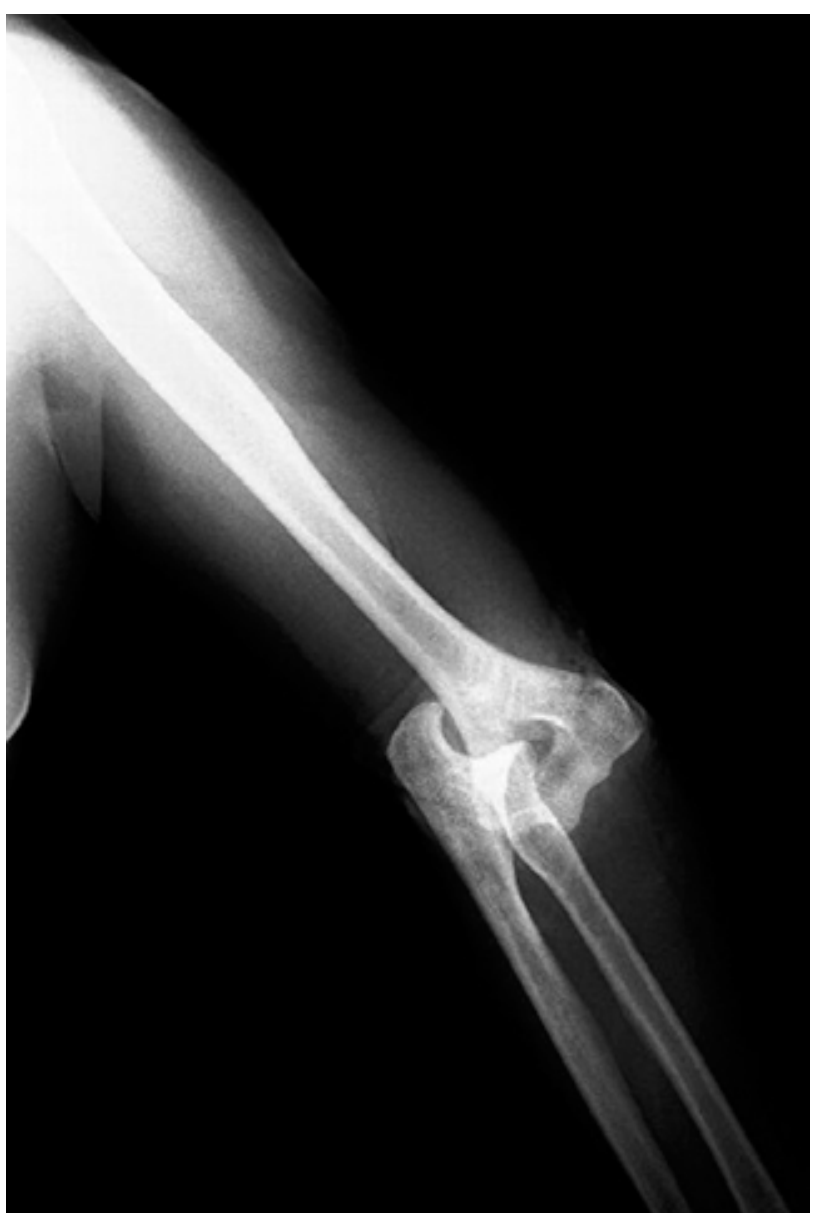

Şekil 1. Basit çıkık.

a) Mutsuz üçlü (terrible triad). Çıkık ile beraber lateral ulnar kollateral bağ yırtılması, radius başı ve koronoid çıkıntı kırığı vardır.

b) Lateral kollateral bağ yırtı̆̆ı ile birlikte koronoid çıkıntı mediyal faset kırığı veya parçalı koronoid kırığı, varus posteromediyal instabilitesine yol açar. ${ }^{[3]}$

Hiperekstansiyon klasik olarak çıkığa yol açan pozisyondur. Hiperekstansiyonda olekranon, olekranon fossaya yaslanırken, troklea da koronoid çıkıntı üzerinde manivela etkisinde bulunur. O'Driscoll ve ark., dirsek çıkığı ile sonlanan farklı yumuşak doku hasarları bildirmişlerdir. Yumuşak doku yetersizlikleri başlıca üç aşamada gerçekleşir:

1) Ulnar lateral kollateral bağ hasarı, ki posterolateral rotator subluksasyon ile sonuçlanır,

2) Anterior ve posteriorda yumuşak dokular daha da hasarlanır ve inkomplet posterolateral çıkık ile sonuçlanır,

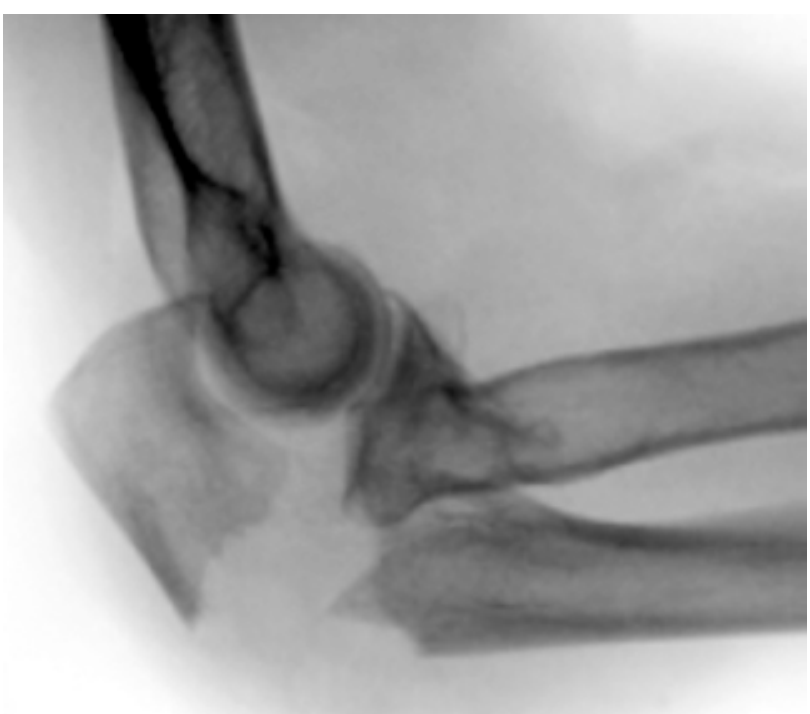

Şekil 2. Kompleks çıkık.

3) a) Ulnar kollateral bağın posterior bandını da içerecek şekilde etrafindaki yumuşak dokular kopar; bu durum sağlam anterior bant ile birlikte posterior çıkık ile sonuçlanır,

b) Tüm mediyal yapılar kopar, fleksör orijin de dahil olmak üzere distal humerustan yumuşak dokular styrilır ve ciddi varus ve valgus instabilitesi olur. ${ }^{[4]}$

Yumuşak doku hasarlarına ilaveten olguların \%25-50'sinde eşlik eden başka yaralanmalar da olur: \%5-10 radius başı kırıkları, \%12 mediyal veya lateral epikondilde avulsiyon kırıkları, \%10 koronoid ve olekranon kırıkları ve diğer eklem içi kırıklar izlenebilir. ${ }^{[5]}$

Çıkığın yönüne göre de (burada ulnanın pozisyonuna göre tanım yapılır):

1. Posterior çıkıklar
a) Posterior,
b) Posteromediyal,
c) Posterolateral

2. Anterior, mediyal, lateral, diverjan çıkıklar görülebilir.

\section{TEDAVi}

Konservatif ve cerrahi olmak üzere ayrılabilir. Ciddi şişlik, kas spazmı, nörovasküler yaralanma ve kemik hasarı yok ise sedasyon altında redüksiyon denenir. Redüksiyon, yeterli kas gevşemesi ve anestezi olmadan zordur. Genellikle olekranon üzerinden hafif 


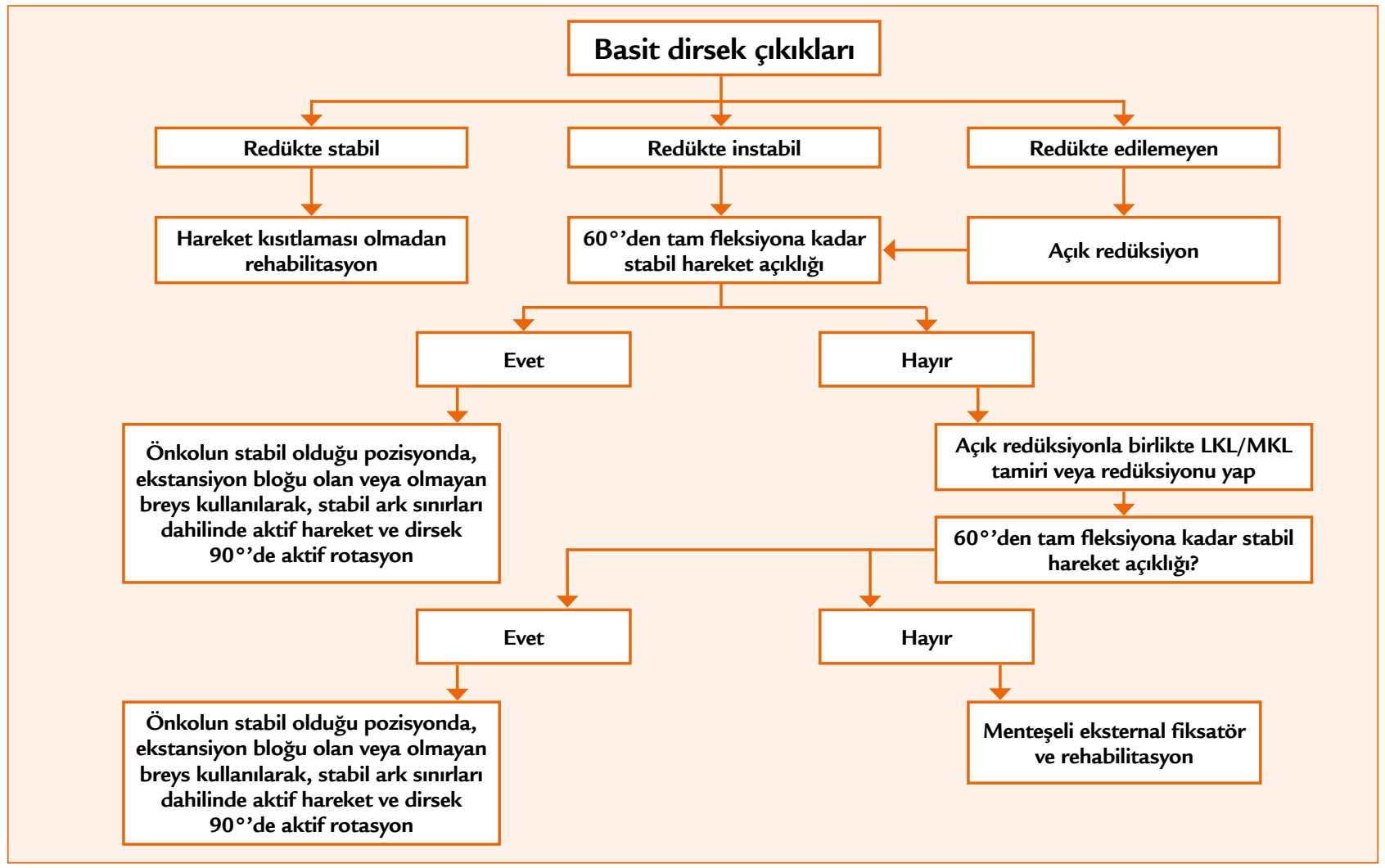

Şekil 3. Dirsek çıkıklarında tedavi algoritması.

bastırılırken, önkol supinasyonda ve dirsek yaklaşık $45^{\circ}$ fleksiyonda iken, longitudinal traksiyon ile redüksiyon sağlanır. Bazı yazarlar, redüksiyon için dirseğin ön ve hiperekstansiyona getirilerek olekranonun kurtarılmasını önerirler; ancak bu durumda median sinir sıkışma riski vardır. ${ }^{[6]}$ Redüksiyon sırasında hastanın çok ağrısının olduğu durumlarda, geç olgularda sedasyon yeterli olmayabilir ve genel veya rejyonel anestezi uygulanmalıdır. Redüksiyon bir türlü sağlanamıyor ise çok zorlamamak gerekir. Nadir olmakla birlikte araya median sinir sıkışabilir ${ }^{[7]}$, brakiyal arter hasarı olabilir. ${ }^{[8]}$ Redüksiyon sonrası nörovasküler muayene tekrar edilmeli ve sonrasında dirsek stabilitesine bakılmalıdır. Redüksiyon sırasında eklemin oturma sesi stabilite açısından değerli bir bulgudur. Çoğu çıkık dirsekler valgus stresine karşı instabildir. Eğer dirsek ekstansiyonda sublukse oluyor veya çıkıyor ise önkol pronasyonda test edilmelidir. Eğer pronasyonda çıkmıyor ise bu pozisyonda menteşeli breys ile takip edilebilir. Posterior çıkıklarda dirsek ekstansiyonda daha instabildir; bu nedenle en az $90^{\circ}$ fleksiyonda tespit edilmelidir. Eğer LKL kopmuş ve MKL sağlam ise dirsek önkol pronasyonda daha stabildir. Eğer MKL kopmuş LKL sağlam ise dirsek önkol supinasyonda daha stabildir.
Redüksiyon sonrası radyolojik kontrol de yapılmalıdır. Redüksiyon sonrası eklem aralığında genişleme var ise arada kondral veya osteokondral bir parça sıkışmış olabilir, ki bu da bir şekilde çıkarılmalıdır.

Basit çıkıklar sonrası, stabilite kontrolü de iyi ise 7-10 gün posterior alçı atel sonrası erken harekete izin verilmelidir. Breys takılan hastalarda ise breys dört hafta kullanılmalıdır.

Basit, akut çıkıklar sonrası açık redüksiyon ihtiyacı nadirdir. Kapalı şekilde redüksiyon sağlanamaz ise, osteokondral bir parça ya da yumuşak doku redüksiyonu engelliyorsa ve kırıkların eşlik ettiği çıkıklarda cerrahi düşünülmelidir. Bazen radius başı kırılarak araya sıkışabilir ${ }^{[9]}$, mediyal epikondil kırıkları redüksiyonu engelleyebilir. Bu gibi durumlarda patolojiye göre giriş yapılır. Örneğin radius başında problem varsa lateral Kocher insizyonu kullanılır. ${ }^{[6]}$ Mutsuz üçlü varsa radius başı tespit ya da replase edilmelidir; mümkün ise koronoid kırı̆gı tespit edilmeli, kapsüler ve ligamentöz yapılar onarılmalı, mediyal kollateral bağ özellikle onarılmalı ve sonrasında menteşeli eksternal fiksatör uygulanmalıdır. ${ }^{[10]}$ Dirsek çıkıklarında tedavi algoritması Şekil 3'te verilmiştir. ${ }^{[3]}$ 


\section{KOMPLIKASYONLAR}

Tekrarlayıcı instabilite, sertlik, miyozitis ossifikans, heterotopik ossifikasyon ve nörovasküler disfonksiyon görülebilir. Tekrarlayıcı çıkıklar yaygın değildir, ancak olursa tedavisi oldukça güçtür. Birçok neden bu durumu oluşturabilir, ki başlıcaları; kollateral bağ hasarları, troklea ya da semilunar çentikte eklem defektleri, koronoid çıkıntı kaynamamaları ve anterior kapsül iyileşme yetersizliğidir.

Tedavide değişik yaklaşımlar mevcuttur. Milch, koronoid çıkıntı ucuna tibial kemik bloğu yerleştirmiş, Reichenheim ise biseps tendonunu koronoid çıkıntıya transfer etmiş̧tir. Kapel, triseps aponörozundan bir şerit ile bir tür çapraz bağ oluşturmuş, Osborne ve Cotterill defektli olduklarına inandıkları posterolateral kapsülü tekrar distal lateral humerusa tespit etmişler, Schwab ve ark. ise daha çok MKL üzerinde durmuşlar ve tekrar tespit veya serbest greft ile rekonstrüksiyon önermişlerdir. ${ }^{[11]}$

Kompleks çıkıklar sonrası dirseğin uzun süre hareketsiz tutulması sonucu eklem sertliği görülebilir. Bu gibi durumlarda iyi bir rehabilitasyon programı uygulanmal[ ${ }^{[12]}$, buna rağmen düzelme olmuyorsa cerrahi olarak artrolizis düşünülmelidir. ${ }^{[13]}$

\section{KAYNAKLAR}

1. Cohen MS, Hastings $\mathrm{H}$. Acute Elbow Dislocation. Evaluation and Management. J Am Acad Orthop Surg 1998;6(1):15-23. Crossref

2. Caldwell GL Jr, Safran MR. Elbow problems in the athlete. Orthop Clin North Am 1995;26(3):465-85.
3. Armstrong AD. Dislocations of the Elbow, Chap. 80. In: Lieberman JR, editor. AAOS Comprehensive Orthopaedic Review. 2009. pp.865-9.

4. O'Driscoll SW, Morrey BF, Korinek S, An KN. Elbow subluxation and dislocation: a spectrum of instability. Clin Orthop Relat Res 1998;(280):186-97. Crossref

5. Burra G, Andrews JR. Acute shoulder and elbow dislocations in the athlete. Orthop Clin North Am 2002;33(3):479-95. Crossref

6. Hobgood ER, Khan SO, Field LD. Acute dislocation of the adult elbow. Hand Clin 2008;24(1):1-7. Crossref

7. Danielsson LG. Median nerve entrapment in elbow dislocation. A case report. Acta Orthop Scand 1986;57(5):450-2. Crossref

8. Ayel JE, Bonnevialle N, Lafosse JM, Pidhorz L, Al Homsy M, Mansat P, Chaufour X, Rongieres M, Bonnevialle P. Acute elbow dislocation with arterial rupture. Analysis of nine cases. Orthop Traumatol Surg Res 2009;95(5):343-51. Crossref

9. Josefsson PO, Gentz CF, Johnell O, Wendeberg B. Dislocations of the elbow and intraarticular fractures. Clin Orthop Relat Res 1989;(246):126-30. Crossref

10. McKee MD, Pugh DMW, Wild LM, Schemitsch EH, King GJW. Standard surgical protocol to treat elbow dislocations with radial head and coronoid fractures. Surgical technique. J Bone Joint Surg Am 2005;87(Suppl 1):22-32. Crossref

11. Jupiter JB, Mehne DK. Trauma to the adult elbow and fractures of the distal humerus, Chap. 37. In: Browner BD, Jupiter JB, Levine AM, Traffin PG, editors. Skeletal Trauma, 1st ed. Vol 2. Philadelphia: WB Saunders Co; 1992. pp.1125-76.

12. Jones V. Conservative management of the post-traumatic stiff elbow: a physiotherapist's perspective. Shoulder Elbow 2016;8(2):134-41. Crossref

13. Cikes A, Jolles BM, Farron A. Open Elbow Arthrolysis for Posttraumatic Elbow Stiffness. J Orthop Trauma 2006;20(6):405-9. Crossref 